\title{
Retraction Note: Seasonal change of air pollution and optimization of social sports public service based on Bayesian network
}

\section{Yao Wang ${ }^{1} \cdot$ Zhanju $\mathrm{Ma}^{2}$}

Published online: 9 November 2021

○) Saudi Society for Geosciences 2021

Retraction Note: Arabian Journal of Geosciences (2021) 14: 1784

https://doi.org/10.1007/s12517-021-08077-0

The Editor-in-Chief and the Publisher have retracted this article because the content of this article is nonsensical. The peer review process was not carried out in accordance with the Publisher's peer review policy. The authors have not responded to correspondence regarding this retraction.

The original article can be found online at https://doi.org/10.1007/ s12517-021-08077-0.

Zhanju Ma

shierzu1011@163.com

1 Cangzhou Normal University, Hebei 061001, China

2 Hebei Women's Vocational College, Hebei 050051, China 